\title{
Association of daily coffee and tea consumption and metabolic syndrome: results from the Polish arm of the HAPIEE study
}

\author{
Giuseppe Grosso • Urszula Stepaniak • Agnieszka Micek • \\ Roman Topor-Mądry $\cdot$ Hynek Pikhart • \\ Krystyna Szafraniec $\cdot$ Andrzej Pająk
}

Received: 9 June 2014/ Accepted: 30 September 2014/Published online: 4 November 2014

(C) The Author(s) 2014. This article is published with open access at Springerlink.com

\begin{abstract}
Purpose The aim of this study was to evaluate whether daily consumption of coffee and tea was associated with components and prevalence of metabolic syndrome (MetS) in the Polish arm of the Health, Alcohol and Psychosocial factors In Eastern Europe cohort study.

Methods A cross-sectional population-based survey including 8,821 adults (51.4\% female) was conducted in Krakow, Poland. Coffee and tea consumption was evaluated using food frequency questionnaires. MetS was defined according to the International Diabetes Federation definition. Linear and logistic regression models were performed to estimate odds ratios and confidence intervals. Results Among high coffee and tea consumers (3 or more cups/day), high prevalence of female gender, young age, medium-high educational and occupational level, high total energy intake, and smoking habit were found. High coffee drinkers had lower BMI, waist circumference, systolic and diastolic blood pressure, triglycerides, and higher HDL cholesterol than those drinking less than 1 cup/day. In contrast, high tea consumers had lower BMI, waist circumference, but not diastolic blood pressure, which was
\end{abstract}

\footnotetext{
G. Grosso (ه)

Department of Clinical and Molecular Biomedicine, Section of Pharmacology and Biochemistry, University of Catania, V.le A. Doria 6, 95125 Catania, Italy

e-mail: giuseppe.grosso@studium.unict.it

G. Grosso · U. Stepaniak · A. Micek · R. Topor-Mądry ·

K. Szafraniec · A. Pająk

Department of Epidemiology and Population Studies,

Jagiellonian University Medical College, Kraków, Poland

H. Pikhart

Department of Epidemiology and Public Health, University College London, London, UK
}

higher than low drinkers. After adjusting for potential confounding factors, both higher coffee and tea consumption were negatively associated with MetS (OR 0.75, $95 \%$ CI $0.66,0.86$ and OR $0.79,95 \%$ CI $0.67,0.92$, respectively). Among specific components of MetS, high coffee consumption was negatively associated with waist circumference, hypertension, and triglycerides, whereas tea consumption with central obesity and fasting plasma glucose in women, but not in men.

Conclusions Coffee and tea consumption was negatively associated with MetS and some of its components.

Keywords Coffee $\cdot$ Tea Metabolic syndrome . Blood pressure - Waist circumference - Dyslipidemia . Hyperglycemia

\section{Introduction}

Metabolic syndrome (MetS) is defined by the presence of a group of cardiovascular risk factors, such as hyperglycemia, dyslipidemia, hypertension, and abdominal obesity, which clustered together are associated with greater cardiovascular disease risk [1, 2]. The prevalence of MetS has increased over recent decades, reaching alarming rates worldwide [3, 4]. However, there are important differences between regions, which could be attributed to diet and lifestyle that specifically differ by country $[5,6]$. A protective effect is attributable, at least in part, to the contents of plant-derived foods and bioactive phytochemicals in the diet. Indeed, the components of MetS have been inversely associated with dietary pattern including polyphenol-rich foods, such as fruit and vegetables as well as olive oil and red wine [7].

Recently, increasing experimental and epidemiological studies pointed out the possible beneficial effects of coffee 
and tea on cardiovascular disease risk [8]. These two beverages are among the most consumed worldwide, with higher amount, especially in non-Mediterranean countries $[9,10]$. Epidemiological studies showed that regular coffee intake improved some components of the MetS, including hypertension and diabetes mellitus [11, 12]. Tea consumption has been reported to protect against cardiovascular disease (CVD) by reducing blood pressure, blood glucose levels, and body weight [13]. The beneficial effects of tea and coffee consumption could be explained by their high content of vitamins and polyphenols, which are suggested to be negatively associated with chronic diseases $[14,15]$. The potential health benefits depend on their antioxidant and antiinflammatory bioactivity, which may contribute to their protective role against CVD [16]. A growing number of studies have suggested that coffee and tea polyphenols may be useful for the prevention of obesity and MetS [17, 18]. Although results of experimental studies are not conclusive, the effects of tea and coffee consumption should be evaluated in the observational studies, since acute administration of caffeinated beverages in clinical trials leads to inconsistent or detrimental effects on health [19].

Studies regarding the association of coffee and tea consumption with MetS are scarce. Some studies conducted in Japan demonstrated a significant inverse correlation between coffee intake and MetS [20-22]. Other studies conducted in the European setting failed to demonstrate any relation [23-25], whereas another study conducted in a Mediterranean area reported a favorable effect [26]. However, investigations conducted on large and wellestablished nutritional cohorts are still lacking.

The aim of this study was to evaluate whether daily consumption of coffee and tea was independently associated with components and prevalence of MetS in a large cohort from the Krakow town in Poland. The association of coffee and tea consumption with multiple markers for MetS, including body mass index (BMI), waist circumference (WC), fasting plasma glucose (FPG), total cholesterol, HDL-cholesterol (HDL-c), LDL-cholesterol (LDL-c), serum triglycerides, and systolic and diastolic blood pressure (SBP and DBP, respectively), was explored.

\section{Subjects and methods}

\section{Study population}

Subjects were participants of the Polish arm of the Health, Alcohol and Psychosocial factors In Eastern Europe (HAPIEE) study, which was a prospective cohort study aimed to investigate the determinants of CVD and other chronic conditions in Central and Eastern Europe. The study protocol with the rationale, design, and methods has been described in detail elsewhere [27]. Briefly, a random sample of 10,728 subjects (aged 45-69 year) was recruited at the baseline survey conducted in 2002-2005 (response ratio of $59 \%$ ) in the urban area of Krakow, Poland. The survey involved completion of structured questionnaires and an examination in clinic. The questionnaires covered health, medical history, health behavior, socioeconomic circumstances, psycho-social factors, and diet. The participants provided written informed consent, and the study protocol was approved by the ethics committee at University College London, UK and by the bioethics committee of the Jagiellonian University (no. KE/99/03/B/284 2).

Among participants who attended the clinical visit ( $n=9,050)$, those with missing outcome measures, with incomplete (more than $50 \%$ of answers missing) or incongruent (energy intake $<500 />4,000 \mathrm{kcal} /$ day for females and $<800 />5,000 \mathrm{kcal} /$ day for males) data regarding dietary information were excluded, resulting in a final sample of 8,821 adults ( $51.4 \%$ female).

\section{Demographic and lifestyle information}

Socio-demographic and lifestyle characteristics included age, gender, educational and occupational level, smoking, and alcohol drinking habits. Educational level was categorized as (1) low (primary/secondary), (2) medium (high school), and (3) high (university). Occupational level was categorized as (1) low (unskilled/unemployed workers), (2) medium (partially skilled workers), and (3) high (skilled workers). Physical activity level was categorized as daily (1) low active [expended energy $<16.7 \mathrm{~kJ}(<4 \mathrm{kcal}) / \mathrm{min}$ ], (2) moderately active [expended energy $16.7-29.3 \mathrm{~kJ}$ (4-7 kcal)/min], and (3) highly active [expended energy $>29.3 \mathrm{~kJ}$ (7 kcal)/min]. Smoking status was categorized as (1) non-smoker and (2) current smoker. Alcohol consumption was categorized as (1) none or moderate drinker $(<12 \mathrm{~g} /$ day $)$ and (2) alcohol drinker (>12 g/day).

\section{Dietary assessment}

Dietary data were collected by using a food frequency questionnaire (FFQ) based on the tool developed by Willett et al. [28] and subsequently adapted in the Whitehall II Study [29]. The FFQs consisted of 148 food and drink items. An instruction manual that included photographs to facilitate the estimation of portion sizes was used. Participants were asked how often, on average, they had consumed that amount of the item during the last 3 months, with nine responses ranging from "never or less than once per month" to "six or more times per day". Moreover, participants were asked to include additional foods and frequency of consumption by manual entry. 
The average beverage consumption was calculated (in $\mathrm{mL}$ ) by following the standard portion sizes used in the study and then converted in 24-h intake. For the sake of simplicity, we categorized coffee and tea consumption according to standard cup of coffee $(150 \mathrm{~mL})$ and tea $(250 \mathrm{~mL})$ in (1) $<1 \mathrm{cup} /$ day, (2) $1-2 \mathrm{cups} /$ day, and (3) 3 or more cups/day.

\section{Clinical measurements}

The physical examination included measurement of height, weight, waist circumference, and blood pressure using standard procedures [27]. MetS was defined according to the International Diabetes Federation definition, as having central obesity (WC $\geq 90 \mathrm{~cm}$ in men and $\geq 80 \mathrm{~cm}$ in women) and any two of the following: (1) triglycerides $>150 \mathrm{mg} / \mathrm{dL}(1.7 \mathrm{mmol} / \mathrm{L})$, or specific treatment for this lipid abnormality; (2) HDL-c $<40 \mathrm{mg} / \mathrm{dL}$ ( $1.03 \mathrm{mmol} / \mathrm{L})$ in males, $<50 \mathrm{mg} / \mathrm{dL}(1.29 \mathrm{mmol} / \mathrm{L})$ in females, or specific treatment for this lipid abnormality; (3) SBP $>130$ or DBP $>85 \mathrm{~mm} \mathrm{Hg}$, or treatment of previously diagnosed hypertension; and (4) FPG $>100 \mathrm{mg} / \mathrm{dL}(5.6 \mathrm{mmol} / \mathrm{L})$, or previously diagnosed type two diabetes or treatment of previously diagnosed diabetes [30].

\section{Statistical analysis}

Continuous variables are presented as means and standard deviations (SDs), categorical variables as frequencies and percentages. Variables were examined for normality and skewness (Kolmogorov and Levene tests). One-way ANOVA using Bonferroni correction and Kruskal-Wallis test was used for comparisons of continuous variables, and Chi-square test was used for categorical variables. Linear trends across the coffee consumption categories were tested by assigning each participant the median of the category and modeling this value as a continuous variable. Multivariable logistic regression models were performed to assess the relationship between metabolic parameters (BMI, WC, HDL-c, LDL-c, total cholesterol, FPG, SBP, and DBP) as dependent variables and coffee and tea consumption categories as exposure variables by odds ratios (ORs) and $95 \%$ confidence intervals (CIs). Gender-specific analyses were also conducted to take into account the natural differences in body composition and caloric needs between men and women. Endpoints were adjusted for gender, age, educational level, occupational level, physical activity, smoking status, alcohol drinking, and total energy intake. $p$ values $<0.05$ (two-tailed) were considered significant. Analyses were performed using SPSS software v17.0 (Chicago, USA).

\section{Results}

Baseline characteristics of the 8,822 subjects included in the analysis by coffee and tea consumption category are presented in Table 1. Among high coffee consumers ( 3 or more cups/day), a higher prevalence of female gender, younger age (average 56.8 years), higher total energy intake, and medium-higher educational and occupational level were found. A significant different distribution was found also according smoking status and alcohol drinking (Table 1). Similar trends were found regarding tea consumption with respect to gender (female) and total energy intake (higher mean intake). High tea consumers were also mostly smokers, not alcohol drinkers, and high physically active.

When examining the association between coffee and tea consumption and various anthropometric measures, a significant inverse trend across categories of coffee consumption was found for BMI $(P<0.001)$, WC $(P<0.001)$, SBP $(P<0.001)$, DBP $(P<0.001)$, triglycerides $(P=0.014)$, and a direct association with HDL-c $(P=0.024)$ and LDL-c $(P=0.045)$ (Table 2$)$. In contrast, significant inverse trend was found for categories of tea drinking and only BMI $(P<0.001)$ and WC $(P=0.036)$ (Table 2).

Both coffee and tea consumption were inversely associated with having MetS (Tables 3, 4). The multivariable regression analysis of overall sample, adjusted for gender, age, educational level, occupational level, physical activity, smoking status, alcohol drinking, total energy intake, and tea consumption, revealed that high coffee consumption ( $>2$ vs. $<1$ cup/day) was significantly associated with several components of MetS, such as WC, blood pressure cut offs, and triglycerides (Table 3). When the analysis was repeated by gender, coffee consumption was inversely related to WC in men, but not in women, whereas among the latter a significant association with hypertension and low HDL-c was found (Table 3). Results about tea consumption were slightly different (Table 4). Despite the high consumption of tea was inversely related with having MetS, the analysis stratified by gender revealed a significant association for men, but not for women. The strongest relation was between tea consumption and central obesity, with a trend over categories of tea consumption in both men and women. Finally, tea consumption was also inversely related to FPG in women, but not in men.

\section{Discussion}

In the present study, we evaluated the relationship between coffee and tea consumption with cardiovascular risk factors 
Table 1 Demographic and lifestyle characteristics of the study sample by coffee and tea frequency of consumption categories $(n=8,821)$

\begin{tabular}{|c|c|c|c|c|c|c|c|c|}
\hline & \multicolumn{3}{|c|}{ Coffee consumption } & \multirow[t]{2}{*}{$P$} & \multicolumn{3}{|c|}{ Tea consumption } & \multirow[t]{2}{*}{$P$} \\
\hline & $<1$ cup/day & 1-2 cups/day & $>2$ cups/day & & $<1$ cup/day & 1-2 cups/day & $>2$ cups/day & \\
\hline $\begin{array}{l}\text { Total } \\
\text { population, } \\
n(\%)\end{array}$ & $2,734(31)$ & $3,695(41.9)$ & $2,392(27.1)$ & - & $1,743(19.8)$ & $5,145(58.3)$ & 1,933 (21.9) & - \\
\hline Gender, $n(\%)$ & & & & 0.004 & & & & 0.006 \\
\hline Male & $1,399(51.2)$ & $1,736(47.0)$ & $1,156(48.3)$ & & $804(46.1)$ & $2,494(48.5)$ & 993 (51.4) & \\
\hline Female & $1,335(48.8)$ & $1,959(53.0)$ & $1,236(51.7)$ & & $939(53.9)$ & $2,651(51.5)$ & 940 (48.6) & \\
\hline $\begin{array}{l}\text { Age (years), } \\
\text { mean (SD) }\end{array}$ & $58.2(7.0)$ & $58.0(7.0)$ & $56.8(6.9)$ & $<0.001$ & $57.8(6.9)$ & $57.7(7.0)$ & $57.6(6.9)$ & 0.654 \\
\hline $\begin{array}{l}\text { Total energy } \\
\text { intake (kcal), } \\
\text { mean (SD) }\end{array}$ & $2,106.2(648.9)$ & $2,127.7(610.7)$ & $2,233.4(661.4)$ & $<0.001$ & $2,086.6(675.6)$ & $2,133.3(616.5)$ & $2,250.2(651.5)$ & $<0.001$ \\
\hline $\begin{array}{l}\text { Educational } \\
\text { level, } n(\%)\end{array}$ & & & & 0.047 & & & & 0.200 \\
\hline Low & 309 (11.3) & $448(12.1)$ & $231(9.7)$ & & $211(12.1)$ & $548(10.7)$ & 229 (11.9) & \\
\hline Medium & $1,620(59.3)$ & $2,197(59.5)$ & $1,437(60.1)$ & & $1,017(58.4)$ & $3,113(60.6)$ & $1,124(58.2)$ & \\
\hline High & $801(29.3)$ & $1,050(28.4)$ & $722(30.2)$ & & $514(29.5)$ & $1,480(28.8)$ & $579(30.0)$ & \\
\hline $\begin{array}{l}\text { Occupational } \\
\text { level, } n(\%)\end{array}$ & & & & 0.034 & & & & 0.449 \\
\hline Low & $1,441(54.5)$ & $1,929(53.5)$ & $1,224(52.4)$ & & $904(53.2)$ & $2,678(53.5)$ & $1,012(53.8)$ & \\
\hline Medium & 892 (33.7) & $1,258(34.9)$ & 875 (37.5) & & $588(34.6)$ & $1,789(35.7)$ & $648(34.4)$ & \\
\hline High & 313 (11.8) & $421(11.7)$ & $235(10.1)$ & & $207(12.2)$ & $540(10.8)$ & $222(11.8)$ & \\
\hline $\begin{array}{l}\text { Current smoking } \\
\text { (yes), } n(\%)\end{array}$ & $2,022(74.1)$ & $2,612(70.9)$ & $1,519(63.7)$ & $<0.001$ & $1,172(67.4)$ & $3,606(70.3)$ & $1,375(71.2)$ & 0.028 \\
\hline $\begin{array}{l}\text { Alcohol drinking } \\
\text { (yes), } n(\%)\end{array}$ & 127 (4.6) & $131(3.5)$ & $121(5.1)$ & 0.010 & $120(6.9)$ & $182(3.5)$ & $77(4.0)$ & $<0.001$ \\
\hline $\begin{array}{l}\text { Physical activity } \\
\text { level, } n(\%)\end{array}$ & & & & 0.657 & & & & 0.015 \\
\hline Low & $729(28.1)$ & 1,039 (29.6) & $632(27.9)$ & & 477 (29.0) & $1,420(29.2)$ & $503(27.1)$ & \\
\hline Moderate & $950(36.7)$ & $1,264(36.0)$ & $832(36.7)$ & & $606(36.8)$ & $1,799(37.0)$ & 641 (34.6) & \\
\hline High & $912(35.2)$ & $1,209(34.4)$ & $800(35.3)$ & & $563(34.2)$ & $1,647(33.8)$ & $711(38.3)$ & \\
\hline
\end{tabular}

and MetS in a large sample of men and women living in Krakow, Poland. Both coffee and tea consumption were negatively associated with MetS. The overall prevalence of MetS in the sample was $27.9 \%$, similar to previous reports from Poland [31-33]. The proportion of MetS in low and high consumers of coffee was 30.2 and $23.7 \%$, respectively. Similar differences were found for tea consumers, for instance, $30.8 \%$ among low consumers and $26.4 \%$ in high consumers.

The relationship between coffee consumption and MetS has not yet been well investigated, and results of previous epidemiological studies are contrasting. Several studies reported that coffee consumption was inversely associated with MetS in the Japanese population [20-22]. On the other hand, studies conducted in central [23, 24] and north [25] European countries reported no relation between coffee consumption and the development of MetS or its components. In contrast, a previous study conducted in a Southern
European region (namely the Mediterranean area) showed a negative (beneficial) association [26]. Epidemiological studies exploring the favorable effect of tea consumption on MetS have reported more univocal results, such as an inverse association [34-36] and others even a therapeutic effect [37-39]. We reported an overall negative association between coffee and tea consumption and MetS, but contrarily to the previous studies, and this association was more remarked for coffee, rather than for tea. The components of MetS that have been found to be more susceptible to consumption of coffee and tea were primarily central obesity, with no differences between men and women, whereas association with cholesterol and glucose metabolisms greatly depended on the type of beverages and gender. Our results confirm in part the findings reported in previous studies assessing that habitual consumptions of tea were favorably associated with triglycerides [40], FPG [41, 42] and body fat [43], whereas coffee was more likely 
Table 2 Anthropometric characteristics and biomarkers of metabolic syndrome of the study sample by categories of coffee and tea consumption

\begin{tabular}{|c|c|c|c|c|c|c|c|c|}
\hline & \multicolumn{3}{|c|}{ Coffee consumption } & \multirow{2}{*}{$\begin{array}{l}P \text { for } \\
\text { trend }\end{array}$} & \multicolumn{3}{|l|}{ Tea consumption } & \multirow{2}{*}{$\begin{array}{l}P \text { for } \\
\text { trend }\end{array}$} \\
\hline & $<1$ cup/day & 1-2 cups/day & $>2$ cups/day & & $<1$ cup/day & 1-2 cups/day & $>2$ cups/day & \\
\hline $\begin{array}{l}\text { Body mass index, } \\
\text { mean (SD) }\end{array}$ & $28.25(4.58)$ & $28.20(4.59)$ & $27.77(4.61)$ & $<0.001$ & $28.55(4.84)$ & $28.05(4.55)$ & $27.84(4.47)$ & $<0.001$ \\
\hline $\begin{array}{l}\text { Waist circumference } \\
(\mathrm{cm}) \text {, mean }(\mathrm{SD})\end{array}$ & $93.34(12.46)$ & $92.43(12.24)$ & $91.62(12.43)$ & $<0.001$ & $93.20(12.60)$ & $92.31(12.26)$ & $92.32(12.45)$ & 0.036 \\
\hline $\begin{array}{l}\text { Systolic blood } \\
\text { pressure }(\mathrm{mmHg}), \\
\text { mean }(\mathrm{SD})\end{array}$ & 139.59 (21.15) & $138.41(21.26)$ & $136.06(20.77)$ & $<0.001$ & $138.49(21.28)$ & $137.74(21.29)$ & $138.87(20.58)$ & 0.531 \\
\hline $\begin{array}{l}\text { Diastolic blood } \\
\text { pressure }(\mathrm{mmHg}), \\
\text { mean }(\mathrm{SD})\end{array}$ & $86.83(12.05)$ & $86.26(11.68)$ & $85.31(11.61)$ & $<0.001$ & 86.37 (11.87) & $85.87(11.75)$ & $86.85(11.81)$ & 0.176 \\
\hline $\begin{array}{l}\text { Glucose }(\mathrm{mmol} / \mathrm{L}), \\
\text { mean }(\mathrm{SD})\end{array}$ & $5.39(1.45)$ & $5.37(1.44)$ & $5.32(1.92)$ & 0.081 & $5.41(1.49)$ & $5.33(1.39)$ & $5.40(2.08)$ & 0.813 \\
\hline $\begin{array}{l}\text { Total cholesterol } \\
(\mathrm{mmol} / \mathrm{L}), \text { mean } \\
\text { (SD) }\end{array}$ & 5.77 (1.07) & $5.83(1.06)$ & $5.83(1.05)$ & 0.072 & $5.84(1.08)$ & $5.81(1.05)$ & $5.80(1.06)$ & 0.290 \\
\hline $\begin{array}{l}\text { HDL-cholesterol } \\
\text { (mmol/L), mean } \\
(\mathrm{SD})\end{array}$ & $1.43(0.37)$ & $1.45(0.39)$ & $1.46(0.37)$ & 0.024 & $1.45(0.39)$ & $1.44(0.37)$ & $1.44(0.38)$ & 0.202 \\
\hline $\begin{array}{l}\text { LDL-cholesterol } \\
\text { (mmol/L), mean } \\
(\mathrm{SD})\end{array}$ & $3.61(0.95)$ & $3.65(0.95)$ & $3.66(0.94)$ & 0.045 & $3.65(0.95)$ & $3.64(0.95)$ & $3.64(0.96)$ & 0.755 \\
\hline $\begin{array}{l}\text { Triglycerides } \\
\text { (mmol/L), mean } \\
\text { (SD) }\end{array}$ & $1.60(0.77)$ & $1.59(0.76)$ & $1.55(0.74)$ & 0.014 & $1.60(0.75)$ & $1.58(0.75)$ & $1.57(0.78)$ & 0.290 \\
\hline
\end{tabular}

associated with improvements in glucose and insulin metabolism [44] as well as with BMI and WC [45].

Although the exact mechanism through which coffee and tea may prevent MetS is still unclear, previous studies suggested that their healthy effects on chronic diseases may depend on the antioxidant compounds contained in both coffee and tea [46]. These beverages contain significant amounts of vitamins and minerals, such as ascorbic acid (vitamin $\mathrm{C}$ ), several $\mathrm{B}$ vitamins, riboflavin, niacin, folic acid, pantothenic acid, magnesium, potassium, manganese, and fluoride [47, 48]. Among other bioactive compounds, polyphenols are among the best candidates to be responsible for the beneficial actions of coffee and tea consumption on various metabolic disorders [49]. The polyphenols found in coffee are hydroxycinnamic acids (such as caffeic and ferulic acids), among which the most effective against CVD have been reported to be isomers of chlorogenic acid [17]. The main polyphenols contained in tea belong to the family of the catechins, flavanols, flavanol glycosides, flavandiols, and depsides [18]. The beneficial effects of polyphenols contained in coffee and tea in preventing chronic diseases (especially CVD) could be due to their ability to ameliorate endothelial function [50], suppress vascular endothelial cell expression of pro-inflammatory cytokines [51], and consequent upregulation of adhesion molecules and monocyte adhesion [52]. Among the other effects, tea has been demonstrated to ameliorate insulin resistance [53], whereas coffee has been associated with adiponectin levels [54]. However, differences in type and content of polyphenols depending on quality of both coffee and tea may result in a stronger beneficial effect of one rather than the other and this issue needs to be investigated further.

Some mechanisms to explain the healthful effects related to caffeine on preventing the MetS have been hypothesized, including sympathetic over activation, antagonism of adenosine receptors, increased norepinephrine release, a sympathomimetic agent that is capable of increasing energy expenditure, and promoting the loss of body fat [55, 56]. On the other hand, other studies failed in to demonstrate such beneficial effects and reported that caffeine may explicate itself favorable effects on the various components of the MetS [57].

Our study has some limitations that should be addressed. First, because of its cross-sectional nature, the associations retrieved in the study do not indicate causality. Reverse causation should be taken into account when exploring behavioral choices that may be influenced by health status. Also, coffee and tea consumption could be influenced by other lifestyle characteristics and 
Table 3 Multivariable adjusted odds ratios $(95 \% \text { confidence interval })^{\mathrm{a}}$ for metabolic syndrome and its individual components by categories of coffee consumption, overall and by gender

\begin{tabular}{|c|c|c|c|c|c|c|}
\hline & \multicolumn{6}{|c|}{ Coffee consumption } \\
\hline & Men, $n(\%)$ & OR $(95 \% \mathrm{CI})^{\mathrm{a}}$ & Women, $n(\%)$ & OR $(95 \% \mathrm{CI})^{\mathrm{a}}$ & Overall, $n(\%)$ & OR $(95 \% \mathrm{CI})^{\mathrm{a}}$ \\
\hline \multicolumn{7}{|c|}{ Metabolic syndrome (yes) } \\
\hline$<1$ cup/day & $397(28.4)$ & 1 & $429(32.1)$ & 1 & $826(30.2)$ & 1 \\
\hline $1-2$ cups/day & $461(26.6)$ & $0.93(0.78-1.10)$ & $608(31.0)$ & $0.93(0.79-1.10)$ & $1,069(28.9)$ & $0.92(0.82-1.04)$ \\
\hline$>2$ cups/day & $268(23.2)$ & $0.82(0.67-0.99)$ & $298(24.1)$ & $0.69(0.57-0.83)$ & $566(23.7)$ & $0.75(0.66-0.86)$ \\
\hline$P$ for trend & & 0.003 & & $<0.001$ & & $<0.001$ \\
\hline \multicolumn{7}{|c|}{ Waist circumference $\geq 90 \mathrm{~cm}$ in men and $\geq 80 \mathrm{~cm}$ in women } \\
\hline$<1$ cup/day & $460(32.9)$ & 1 & $625(46.8)$ & 1 & $1,085(39.7)$ & 1 \\
\hline 1-2 cups/day & $512(29.5)$ & $0.85(0.72-1.00)$ & $904(46.1)$ & $1.02(0.88-1.19)$ & $1,416(38.3)$ & $0.93(0.83-1.04)$ \\
\hline$>2$ cups/day & $316(27.3)$ & $0.81(0.68-0.98)$ & $524(42.4)$ & $0.90(0.76-1.07)$ & $840(35.1)$ & $0.86(0.75-0.97)$ \\
\hline$P$ for trend & & 0.002 & & 0.210 & & 0.001 \\
\hline \multicolumn{7}{|c|}{ Systolic blood pressure $\geq 130 \mathrm{mmHg}$ or diastolic blood pressure $\geq 85 \mathrm{mmHg}$ or hypertensive treatment } \\
\hline$<1$ cup/day & $963(68.8)$ & 1 & $802(60.1)$ & 1 & $1,765(64.6)$ & 1 \\
\hline $1-2$ cups/day & $1,140(65.7)$ & $0.89(0.75-1.04)$ & $1,112(56.8)$ & $0.92(0.79-1.08)$ & $2,252(60.9)$ & $0.90(0.80-1.01)$ \\
\hline$>2$ cups/day & $727(62.9)$ & $0.88(0.74-1.06)$ & $597(48.3)$ & $0.70(0.59-0.83)$ & $1,324(55.4)$ & $0.78(0.69-0.88)$ \\
\hline$P$ for trend & & 0.002 & & $<0.001$ & & $<0.001$ \\
\hline \multicolumn{7}{|c|}{ HDL-cholesterol $<40 \mathrm{mg} / \mathrm{dL}$ in $\mathrm{men}$ and $<50 \mathrm{mg} / \mathrm{dL}$ in women } \\
\hline$<1$ cup/day & $265(18.9)$ & 1 & $350(26.2)$ & 1 & $615(22.5)$ & 1 \\
\hline $1-2$ cups/day & $335(19.3)$ & $1.01(0.84-1.22)$ & $503(25.7)$ & $0.93(0.79-1.10)$ & $838(22.7)$ & $0.97(0.85-1.10)$ \\
\hline$>2$ cups/day & $220(19.0)$ & $1.02(0.83-1.26)$ & $282(22.8)$ & $0.78(0.65-0.95)$ & $502(21.0)$ & $0.88(0.77-1.02)$ \\
\hline$P$ for trend & & 0.942 & & 0.049 & & 0.210 \\
\hline \multicolumn{7}{|c|}{ Tryglicerides $\geq 150 \mathrm{mg} / \mathrm{dL}$} \\
\hline$<1$ cup/day & $669(47.8)$ & 1 & $614(46.0)$ & 1 & $1,283(46.9)$ & 1 \\
\hline $1-2$ cups/day & $871(50.2)$ & $1.13(0.98-1.31)$ & $877(44.8)$ & $0.95(0.82-1.11)$ & $1,748(47.3)$ & $1.03(0.93-1.15)$ \\
\hline$>2$ cups/day & $542(46.9)$ & $0.96(0.81-1.13)$ & $459(37.1)$ & $0.77(0.64-0.91)$ & $1,001(41.8)$ & $0.86(0.76-0.97)$ \\
\hline$P$ for trend & & 0.718 & & $<0.001$ & & $<0.001$ \\
\hline \multicolumn{7}{|c|}{ Fasting plasma glucose $\geq 100 \mathrm{mg} / \mathrm{dL}$ or diabetes treatment } \\
\hline$<1$ cup/day & $169(12.1)$ & 1 & $113(8.5)$ & 1 & $282(10.3)$ & 1 \\
\hline $1-2$ cups/day & $204(11.8)$ & $0.94(0.74-1.18)$ & $180(9.2)$ & $1.10(0.84-1.43)$ & $384(10.4)$ & $0.99(0.83-1.18)$ \\
\hline$>2$ cups/day & $125(10.8)$ & $0.97(0.75-1.26)$ & $74(6.0)$ & $0.80(0.58-1.11)$ & $199(8.3)$ & $0.90(0.73-1.10)$ \\
\hline$P$ for trend & & 0.328 & & 0.250 & & 0.020 \\
\hline
\end{tabular}

${ }^{a}$ Adjusted for gender (except when analyses were stratified by sex), age, educational level, occupational level, physical activity, smoking status, alcohol drinking, total energy intake, and tea consumption

not be equally distributed by social status. Adjustment for smoking status and education, which was done in our analysis, could not be sufficient to control the confounding effect of background characteristics. Second, the question regarding tea consumption was not specific for different types of tea. Despite the participants were allowed to add supplementary foods, such as green and herbal teas, the most of them did not differentiate between types of tea, thus not allowing us to assess possible differences on effects. Moreover, dietary information was self-reported, which may have led to recall bias. Finally, health information of individuals not included in the analysis due to lack of blood samples should be taken into account when considering our results. However, despite these limitations, our findings remain of significant value, since this was the first study describing the relationship between consumption of coffee and tea and components of MetS in a large sample from East Europe.

In conclusion, a significant negative association between coffee consumption and prevalence of MetS both in men and in women was found, whereas tea consumption was associated with MetS only in men. High coffee and tea consumption were also associated with a decreased prevalence of central obesity and better cholesterol and glucose metabolism. These findings reinforce the hypothesis on the possible health benefits of polyphenols. Due to methodological limitations, we cannot exclude that the observed 
Table 4 Multivariable adjusted odds ratios $(95 \% \text { confidence interval })^{\mathrm{a}}$ for metabolic syndrome and its individual components by categories of tea consumption, overall and by gender

\begin{tabular}{|c|c|c|c|c|c|c|}
\hline & \multicolumn{6}{|c|}{ Tea consumption } \\
\hline & Men, $n(\%)$ & OR $(95 \% \mathrm{CI})^{\mathrm{a}}$ & Women, $n(\%)$ & OR $(95 \% \mathrm{CI})^{\mathrm{a}}$ & Overall, $n(\%)$ & OR $(95 \% \mathrm{CI})^{\mathrm{a}}$ \\
\hline \multicolumn{7}{|c|}{ Metabolic syndrome (yes) } \\
\hline$<1$ cup/day & $242(30.1)$ & 1 & $295(31.4)$ & 1 & $537(30.8)$ & 1 \\
\hline $1-2$ cups/day & $637(25.5)$ & $0.79(0.65-0.95)$ & $777(29.3)$ & $0.89(0.75-1.07)$ & $1,414(27.5)$ & $0.84(0.74-0.96)$ \\
\hline$>2$ cups/day & $247(24.9)$ & $0.75(0.60-0.93)$ & $263(28.0)$ & $0.82(0.65-1.01)$ & $510(26.4)$ & $0.79(0.67-0.92)$ \\
\hline$P$ for trend & & 0.017 & & 0.042 & & 0.003 \\
\hline \multicolumn{7}{|c|}{ Waist circumference $\geq 90 \mathrm{~cm}$ in men and $\geq 80 \mathrm{~cm}$ in women } \\
\hline$<1$ cup/day & $269(33.5)$ & 1 & $472(50.3)$ & 1 & $741(42.5)$ & 1 \\
\hline 1-2 cups/day & $731(29.3)$ & $0.78(0.65-0.93)$ & $1,186(44.7)$ & $0.80(0.68-0.95)$ & 1,917 (37.3) & $0.79(0.70-0.90)$ \\
\hline$>2$ cups/day & $288(29.0)$ & $0.73(0.59-0.90)$ & $395(42.0)$ & $0.71(0.58-0.87)$ & $683(35.3)$ & $0.73(0.63-0.84)$ \\
\hline$P$ for trend & & 0.052 & & $<0.001$ & & $<0.001$ \\
\hline \multicolumn{7}{|c|}{ Systolic blood pressure $\geq 130 \mathrm{mmHg}$ or diastolic blood pressure $\geq 85 \mathrm{mmHg}$ or hypertensive treatment } \\
\hline$<1$ cup/day & $546(67.9)$ & 1 & $535(57.0)$ & 1 & $1,081(62.0)$ & 1 \\
\hline $1-2$ cups/day & $1,597(64.0)$ & $0.85(0.71-1.02)$ & $1,452(54.8)$ & $0.89(0.75-1.05)$ & $3,049(59.3)$ & $0.87(0.77-0.99)$ \\
\hline$>2$ cups/day & $687(69.2)$ & $1.09(0.88-1.36)$ & $524(55.7)$ & $0.96(0.78-1.17)$ & $1,211(62.6)$ & $1.02(0.88-1.18)$ \\
\hline$P$ for trend & & 0.415 & & 0.592 & & 0.614 \\
\hline \multicolumn{7}{|c|}{ HDL-c $<40 \mathrm{mg} / \mathrm{dL}$ in men and $<50 \mathrm{mg} / \mathrm{dL}$ in women } \\
\hline$<1$ cup/day & $163(20.3)$ & 1 & $215(22.9)$ & 1 & $378(21.7)$ & 1 \\
\hline $1-2$ cups/day & $470(18.8)$ & $0.92(0.75-1.14)$ & $690(26.0)$ & $1.18(0.98-1.42)$ & $1,160(22.5)$ & $1.06(0.93-1.22)$ \\
\hline$>2$ cups/day & $187(18.8)$ & $0.91(0.71-1.17)$ & $230(24.5)$ & $1.03(0.82-1.29)$ & $417(21.6)$ & $0.99(0.84-1.17)$ \\
\hline$P$ for trend & & 0.466 & & 0.432 & & 0.902 \\
\hline \multicolumn{7}{|c|}{ Tryglicerides $\geq 150 \mathrm{mg} / \mathrm{dL}$} \\
\hline$<1 \mathrm{cup} / \mathrm{cup} /$ day & $414(51.5)$ & 1 & $392(41.7)$ & 1 & $806(46.2)$ & 1 \\
\hline $1-2$ cups/day & $1,202(48.2)$ & $0.92(0.78-1.09)$ & $1,160(43.8)$ & $1.11(0.94-1.31)$ & $2,362(45.9)$ & $1.01(0.90-1.13)$ \\
\hline$>2$ cups/day & $466(46.9)$ & $0.86(0.71-1.05)$ & $398(42.3)$ & $1.01(0.83-1.23)$ & $864(44.7)$ & $0.93(0.81-1.07)$ \\
\hline$P$ for trend & & 0.060 & & 0.795 & & 0.339 \\
\hline \multicolumn{7}{|c|}{ Fasting plasma glucose $\geq 100 \mathrm{mg} / \mathrm{dL}$ or diabetes treatment } \\
\hline$<1$ cup/day & $96(11.9)$ & 1 & $94(10.0)$ & 1 & $190(10.9)$ & 1 \\
\hline $1-2$ cups/day & $296(11.9)$ & $0.96(0.74-1.24)$ & $203(7.7)$ & $0.74(0.56-0.97)$ & $499(9.7)$ & $0.85(0.71-1.03)$ \\
\hline$>2$ cups/day & $106(10.7)$ & $0.87(0.64-1.19)$ & $70(7.4)$ & $0.70(0.49-0.99)$ & $176(9.1)$ & $0.79(0.63-1.00)$ \\
\hline$P$ for trend & & 0.378 & & 0.042 & & 0.070 \\
\hline
\end{tabular}

${ }^{a}$ Adjusted for gender (except when analyses were stratified by sex), age, educational level, occupational level, physical activity, smoking status, alcohol drinking, total energy intake, and coffee consumption

associations on coffee/tea and MS are due to other healthy lifestyle behaviors, and further prospective studies are needed to better adjust for potential confounding factors.

Acknowledgments The study has been funded by the Wellcome Trust (Grants 064947/Z/01/Z and 081081/Z/06/Z), US National Institute on Ageing (Grant 1R01 AG23522-01) and the MacArthur Foundation Initiative on Social Upheaval and Health (award 71208). Giuseppe Grosso was supported by the International Ph.D. Program in Neuropharmacology, University Medical School of Catania, Catania, Italy.

Conflict of interest The authors have no conflicts of interest to disclose.
Open Access This article is distributed under the terms of the Creative Commons Attribution License which permits any use, distribution, and reproduction in any medium, provided the original author(s) and the source are credited.

\section{References}

1. Eckel RH, Grundy SM, Zimmet PZ (2005) The metabolic syndrome. Lancet 365:1415-1428

2. Grundy SM, Cleeman JI, Daniels SR, Donato KA, Eckel RH, Franklin BA, Gordon DJ, Krauss RM, Savage PJ, Smith SC Jr, Spertus JA, Costa F (2005) Diagnosis and management of the metabolic syndrome: an American Heart Association/National 
Heart, Lung, and Blood Institute Scientific Statement. Circulation 112:2735-2752

3. Ford ES, Giles WH, Dietz WH (2002) Prevalence of the metabolic syndrome among US adults: findings from the third National Health and Nutrition Examination Survey. JAMA 287:356-359

4. Hu G, Qiao Q, Tuomilehto J, Balkau B, Borch-Johnsen K, Pyorala K (2004) Prevalence of the metabolic syndrome and its relation to all-cause and cardiovascular mortality in nondiabetic European men and women. Arch Intern Med 164:1066-1076

5. Grosso G, Mistretta A, Frigiola A, Gruttadauria S, Biondi A, Basile F, Vitaglione P, D’Orazio N, Galvano F (2014) Mediterranean diet and cardiovascular risk factors: a systematic review. Crit Rev Food Sci Nutr 54:593-610

6. Buscemi S, Sprini D, Grosso G, Galvano F, Nicolucci A, Lucisano G, Massenti FM, Amodio E, Rini GB (2014) Impact of lifestyle on metabolic syndrome in apparently healthy people. Eat Weight Disord 19:225-232

7. Grosso G, Pajak A, Mistretta A, Marventano S, Raciti T, Buscemi S, Drago F, Scalfi L, Galvano F (2014) Protective role of the Mediterranean diet on several cardiovascular risk factors: evidence from Sicily, southern Italy. Nutr Met Cardiovasc Discov 24:370-377

8. Bohn SK, Ward NC, Hodgson JM, Croft KD (2012) Effects of tea and coffee on cardiovascular disease risk. Food Funct 3:575-591

9. Thompson WG (1994) Coffee: brew or bane? Am J Med Sci 308:49-57

10. Weisburger JH (1997) Tea and health: a historical perspective. Cancer Lett 114:315-317

11. Jiang X, Zhang D, Jiang W (2014) Coffee and caffeine intake and incidence of type 2 diabetes mellitus: a meta-analysis of prospective studies. Eur J Nutr 53:25-38

12. Steffen M, Kuhle C, Hensrud D, Erwin PJ, Murad MH (2012) The effect of coffee consumption on blood pressure and the development of hypertension: a systematic review and metaanalysis. J Hypertens 30:2245-2254

13. Psaltopoulou T, Ilias I, Alevizaki M (2010) The role of diet and lifestyle in primary, secondary, and tertiary diabetes prevention: a review of meta-analyses. Rev Diabet Stud 7:26-35

14. Grosso G, Bei R, Mistretta A, Marventano S, Calabrese G, Masuelli L, Giganti MG, Modesti A, Galvano F, Gazzolo D (2013) Effects of vitamin C on health: a review of evidence. Front Biosci (Landmark Ed) 18:1017-1029

15. Godos J, Pluchinotta FR, Marventano S, Buscemi S, Li Volti G, Galvano F, Grosso G (2014) Coffee components and cardiovascular risk: beneficial and detrimental effects. Int J Food Sci Nutr 21:1-12

16. Barnes S, Prasain J, D'Alessandro T, Arabshahi A, Botting N, Lila MA, Jackson G, Janle EM, Weaver CM (2011) The metabolism and analysis of isoflavones and other dietary polyphenols in foods and biological systems. Food Funct 2:235-244

17. Meng S, Cao J, Feng Q, Peng J, Hu Y (2013) Roles of chlorogenic acid on regulating glucose and lipids metabolism: a review. Evid Based Complement Alternat Med 2013:801457

18. Islam MA (2012) Cardiovascular effects of green tea catechins: progress and promise. Recent Pat Cardiovasc Drug Discov 7:88-99

19. Geleijnse JM (2008) Habitual coffee consumption and blood pressure: an epidemiological perspective. Vasc Health Risk Manag 4:963-970

20. Matsuura H, Mure K, Nishio N, Kitano N, Nagai N, Takeshita T (2012) Relationship between coffee consumption and prevalence of metabolic syndrome among Japanese civil servants. J Epidemiol 22:160-166

21. Hino A, Adachi H, Enomoto M, Furuki K, Shigetoh Y, Ohtsuka M, Kumagae S, Hirai Y, Jalaldin A, Satoh A, Imaizumi T (2007)
Habitual coffee but not green tea consumption is inversely associated with metabolic syndrome: an epidemiological study in a general Japanese population. Diabetes Res Clin Pract 76:383-389

22. Takami H, Nakamoto M, Uemura H, Katsuura S, Yamaguchi M, Hiyoshi M, Sawachika F, Juta T, Arisawa K (2013) Inverse correlation between coffee consumption and prevalence of metabolic syndrome: baseline survey of the Japan Multi-Institutional Collaborative Cohort (J-MICC) Study in Tokushima, Japan. J Epidemiol 23:12-20

23. Driessen MT, Koppes LL, Veldhuis L, Samoocha D, Twisk JW (2009) Coffee consumption is not related to the metabolic syndrome at the age of 36 years: the Amsterdam Growth and Health Longitudinal Study. Eur J Clin Nutr 63:536-542

24. Balk L, Hoekstra T, Twisk J (2009) Relationship between longterm coffee consumption and components of the metabolic syndrome: the Amsterdam Growth and Health Longitudinal Study. Eur J Epidemiol 24:203-209

25. Hostmark AT (2010) The Oslo health study: soft drink intake is associated with the metabolic syndrome. Appl Physiol Nutr Metab 35:635-642

26. Grosso G, Marventano S, Galvano F, Pajak A, Mistretta A (2014) Factors associated with metabolic syndrome in a Mediterranean population: role of caffeinated beverages. J Epidemiol 24:327-333

27. Peasey A, Bobak M, Kubinova R, Malyutina S, Pajak A, Tamosiunas A, Pikhart H, Nicholson A, Marmot M (2006) Determinants of cardiovascular disease and other non-communicable diseases in Central and Eastern Europe: rationale and design of the HAPIEE study. BMC Public Health 6:255

28. Brunner E, Stallone D, Juneja M, Bingham S, Marmot M (2001) Dietary assessment in Whitehall II: comparison of $7 \mathrm{~d}$ diet diary and food-frequency questionnaire and validity against biomarkers. Br J Nutr 86:405-414

29. Willett WC, Sampson L, Stampfer MJ, Rosner B, Bain C, Witschi J, Hennekens CH, Speizer FE (1985) Reproducibility and validity of a semiquantitative food frequency questionnaire. Am J Epidemiol 122:51-65

30. Alberti KG, Zimmet P, Shaw J (2006) Metabolic syndrome-a new world-wide definition. A consensus statement from the international diabetes federation. Diabet Med 23:469-480

31. Janszky I, Vatten L, Romundstad P, Laugsand LE, Bjorngard JH, Manczuk M, Zatonski WA (2011) Metabolic syndrome in Poland-the PONS Study. Ann Agric Environ Med 18:270-272

32. Ilow R, Regulska-Ilow B, Rozanska D, Kowalisko A, Biernat J (2012) Prevalence of metabolic syndrome among 40- and 50-year-old inhabitants of Wroclaw, Poland. Ann Agric Environ Med 19:551-556

33. Szurkowska M, Szafraniec K, Gilis-Januszewska A, Pach D, Krzentowska A, Szybinski Z, Huszno B (2006) Prevalence of the metabolic syndrome and its components in adult inhabitants of Krakow. Przegl Lek 63:733-737

34. Zuo H, Shi Z, Hu X, Wu M, Guo Z, Hussain A (2009) Prevalence of metabolic syndrome and factors associated with its components in Chinese adults. Metabolism 58:1102-1108

35. Vernarelli JA, Lambert JD (2013) Tea consumption is inversely associated with weight status and other markers for metabolic syndrome in US adults. Eur J Nutr 52:1039-1048

36. Chang CS, Chang YF, Liu PY, Chen CY, Tsai YS, Wu CH (2012) Smoking, habitual tea drinking and metabolic syndrome in elderly men living in rural community: the Tianliao old people (TOP) study 02. PLoS One 7:e38874

37. Hashizume C, Kishimoto Y, Kanahori S, Yamamoto T, Okuma $\mathrm{K}$, Yamamoto K (2012) Improvement effect of resistant maltodextrin in humans with metabolic syndrome by continuous administration. J Nutr Sci Vitaminol (Tokyo) 58:423-430 
38. Vieira Senger AE, Schwanke CH, Gomes I, Valle Gottlieb MG (2012) Effect of green tea (Camellia sinensis) consumption on the components of metabolic syndrome in elderly. J Nutr Health Aging 16:738-742

39. Kubota K, Sumi S, Tojo H, Sumi-Inoue Y, I-Chin H, Oi Y, Fujita $H$, Urata $H$ (2011) Improvements of mean body mass index and body weight in preobese and overweight Japanese adults with black Chinese tea (Pu-Erh) water extract. Nutr Res 31:421-428

40. Tokunaga S, White IR, Frost C, Tanaka K, Kono S, Tokudome S, Akamatsu T, Moriyama T, Zakouji H (2002) Green tea consumption and serum lipids and lipoproteins in a population of healthy workers in Japan. Ann Epidemiol 12:157-165

41. Polychronopoulos E, Zeimbekis A, Kastorini CM, Papairakleous N, Vlachou I, Bountziouka V, Panagiotakos DB (2008) Effects of black and green tea consumption on blood glucose levels in nonobese elderly men and women from Mediterranean Islands (MEDIS epidemiological study). Eur J Nutr 47:10-16

42. Panagiotakos DB, Lionis C, Zeimbekis A, Gelastopoulou K, Papairakleous N, Das UN, Polychronopoulos E (2009) Long-term tea intake is associated with reduced prevalence of (type 2) diabetes mellitus among elderly people from Mediterranean islands: MEDIS epidemiological study. Yonsei Med J 50:31-38

43. Wu CH, Lu FH, Chang CS, Chang TC, Wang RH, Chang CJ (2003) Relationship among habitual tea consumption, percent body fat, and body fat distribution. Obes Res 11:1088-1095

44. Natella F, Scaccini C (2012) Role of coffee in modulation of diabetes risk. Nutr Rev 70:207-217

45. Bouchard DR, Ross R, Janssen I (2010) Coffee, tea and their additives: association with BMI and waist circumference. Obes Facts 3:345-352

46. Sae-tan S, Grove KA, Lambert JD (2011) Weight control and prevention of metabolic syndrome by green tea. Pharmacol Res 64:146-154

47. Suzuki Y, Miyoshi N, Isemura M (2012) Health-promoting effects of green tea. Proc Jpn Acad Ser B Phys Biol Sci 88:88-101

48. Higdon JV, Frei B (2006) Coffee and health: a review of recent human research. Crit Rev Food Sci Nutr 46:101-123
49. Grosso G, Stepaniak U, Topor-Mądry R, Szafraniec K, Pająk A (2014) Estimated dietary intake and major food sources of polyphenols in the Polish arm of the HAPIEE study. Nutrition 30:1398-1403

50. Buscemi S, Verga S, Batsis JA, Tranchina MR, Belmonte S, Mattina A, Re A, Rizzo R, Cerasola G (2009) Dose-dependent effects of decaffeinated coffee on endothelial function in healthy subjects. Eur J Clin Nutr 63:1200-1205

51. Buscemi S, Batsis JA, Arcoleo G, Verga S (2010) Coffee and endothelial function: a battle between caffeine and antioxidants? Eur J Clin Nutr 64:1242-1243

52. Andriantsitohaina R, Auger C, Chataigneau T, Etienne-Selloum N, Li H, Martinez MC, Schini-Kerth VB, Laher I (2012) Molecular mechanisms of the cardiovascular protective effects of polyphenols. Br J Nutr 108:1532-1549

53. Wu LY, Juan CC, Hwang LS, Hsu YP, Ho PH, Ho LT (2004) Green tea supplementation ameliorates insulin resistance and increases glucose transporter IV content in a fructose-fed rat model. Eur J Nutr 43:116-124

54. Imatoh $\mathrm{T}$, Tanihara S, Miyazaki M, Momose $\mathrm{Y}$, Uryu Y, Une $\mathrm{H}$ (2011) Coffee consumption but not green tea consumption is associated with adiponectin levels in Japanese males. Eur J Nutr 50:279-284

55. Westerterp-Plantenga M, Diepvens K, Joosen AM, Berube-Parent S, Tremblay A (2006) Metabolic effects of spices, teas, and caffeine. Physiol Behav 89:85-91

56. Acheson KJ, Gremaud G, Meirim I, Montigon F, Krebs Y, Fay LB, Gay LJ, Schneiter P, Schindler C, Tappy L (2004) Metabolic effects of caffeine in humans: lipid oxidation or futile cycling? Am J Clin Nutr 79:40-46

57. Buscemi S, Verga S, Batsis JA, Donatelli M, Tranchina MR, Belmonte S, Mattina A, Re A, Cerasola G (2010) Acute effects of coffee on endothelial function in healthy subjects. Eur J Clin Nutr 64:483-489 